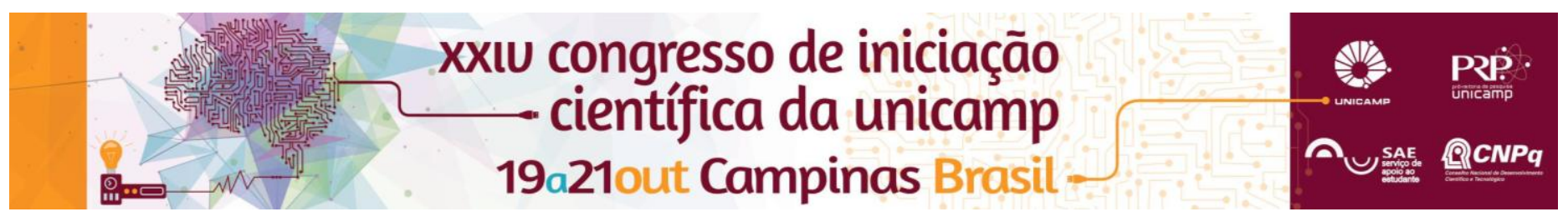

\title{
O controle da Dengue sob a ótica Bioética
}

\author{
Andréa Ap. Romano de Souza Rodrigues*, Rubens Bedrikow
}

\begin{abstract}
Resumo
Esta pesquisa, fomentada pelo Centro de Bioética do Conselho Regional de Medicina do Estado de São Paulo (Cremesp), analisou ações, controle social e dilemas bioéticos relacionados ao controle da Dengue. Utilizou-se metodologia qualitativa - grupo focal e entrevistas junto ao Conselho Municipal de Saúde de Campinas, São Paulo. Concluímos que as ações de Saúde Pública visando o controle da dengue devem se pautar pela Bioética Sanitária. Gestores, trabalhadores e usuários devem agir no sentido priorizar políticas que privilegiem o maior número de pessoas, por maior tempo possível, e que resultem nas melhores consequências para toda a coletividade, não deixando que interesses particulares, corporativos ou partidários coloquem em risco seu compromisso ético. Entendemos ser necessário construir novos padrões de relação entre usuários e gestores, e também entre a União, estados e municípios, baseados na Bioética e na co-gestão
\end{abstract}

\section{Palavras-chave: \\ Dengue. Bioética. Saúde Pública}

\section{Introdução}

Em 2015, o país viveu a maior epidemia de Dengue de sua história com cerca de 1.500 .000 registros e mais de 800 mortes. Campinas se foi a cidade de maior incidência no Brasil com pouco mais de 65.000 casos.

Conflitos que opõem interesses privados/individuais e públicos/coletivos no campo da saúde interessam à Bioética que prioriza temas públicos e coletivos em detrimento de questões específicas, privadas e individuais.

A participação da comunidade é uma diretriz organizativa do Sistema Único de Saúde (SUS), assegurada pela Constituição Federal e regulada pela Lei 8.142/90 e ocorre mediante a participação dos segmentos sociais organizados nas Conferências e nos Conselhos de Saúde, nas três esferas de governo, e através da participação em colegiados de gestão nos serviços de saúde. A atuação dos cidadãos nesses espaços visa influenciar a definição e execução das políticas públicas. ${ }^{2}$ O objetivo geral deste trabalho foi analisar as ações de controle da Dengue sob a ótica da Bioética Sanitária e conhecer os principais dilemas bioéticos relacionados ao controle da doença.

\section{Resultados e Discussão}

Utilizou-se metodologia qualitativa com grupos focais e entrevistas junto aos conselheiros representantes de usuários, gestores e trabalhadores da saúde no Conselho Municipal de Saúde de Campinas (CMS).

Conselheiros representantes de usuários e de trabalhadores consideraram as ações de prevenção insuficientes, e fatores significativos para isso foram: a exoneração de agentes de controle ambiental, ausência de vigilância permanente de criadouros de Aedes aegypt e escassas campanhas de educação.

Para representandes dos gestores, a população continua produzindo criadouros do mosquito em seus imóveis, dificultando a erradicação da epidemia e o acesso de agentes ao interior de seus imóveis. Os conselheiros entrevistados também apontaram dilemas éticos diante do instrumento judicial que autoriza a entrada de agentes de saúde em imóveis particulares sem autorização do proprietário. Alertaram para o fato de que, a depender da forma como a lei é utilizada, pode perder sua função primordial de combate ao vetor para transformar-se em instrumento de propaganda do governo.

\section{Conclusões}

Um dos riscos inerentes ao distanciamento entre gestores e usuários é a possibilidade das políticas públicas serem construídas de modo reducionista, transformando problemas sanitários complexos em desvios de conduta individuais, transferindo a responsabilidade do Estado para o cidadão que mantém criadouros e recusa visitas de agentes de saúde desconsiderando a autonomia dos sujeitos, deixando de aproveitá-la no sentido de empoderar o cidadão como importante adjuvante no combate aos criadouros. A genuína adesão e efetiva participação da população para uma iniciativa é obtida à medida que ela seja capaz de entender que esse processo atende seu interesse direto e de perceber que isso ocorrerá à medida em que cada um exercer seu protagonismo. ${ }^{3}$

Mais do que espaços de polêmicas, os Conselhos de Saúde devem funcionar em co-gestão, participativa e propositiva, e não se limitar a disputas entre os que executam e os que fiscalizam, ainda que se compreenda que as estratégias de combate à Dengue não se restringem a medidas puramente técnicas, mas carregam em si elementos éticos e políticos indissociáveis.

\section{Agradecimentos}

Ao Centro de Bioética do Conselho Regional de Medicina do Estado de São Paulo (Cremesp) pelo financiamento através do Programa de Bolsa de Pesquisa à graduandos em medicina.

${ }^{1}$ Brasil, Ministério da Saúde, Secretaria de Vigilância em Saúde. Boletim Epidemiológico 2015. Disponível em: <http://portalsaude.saude.gov.br $>$ Acesso em 23 mai 2016.

${ }^{2}$ Porto, D. e Garrafa, V.; A influência da reforma sanitária na construção das bioéticas brasileiras. Ciência \& Saúde Coletiva. Rio de Janeiro, v. 16, n. 1, p. 719-29, 2011.

${ }^{3}$ Schramm, F.R.; Kottow, M. Principios bioéticos en salud pública: limitaciones y propuestas. Cadernos de Saúde Pública, Rio de Janeiro, v. 17, n. 4, p. 949-956, 2001 